\title{
Assessing Privacy Protection in Alumni Service
}

\author{
Kittisak Sa-Adaem and Yunyong Teng-Amnuay
}

\begin{abstract}
Most alumni do not realize their personal information should be protected. The problem is exacerbated by the lack in expertise on privacy issues and budget constraints in designing and enhancing privacy for alumni system. This research aims to provide an assessment guideline, called $7 \mathrm{C}$, based on generic features, privacy patterns, privacy legal constraints, and privacy enhancing technologies (PETs), that will be helpful for software designer, developer, auditor, and end-user to deal with various aspects of privacy protections in their system. We selected Elgg, a popular open source social network software as the test system. We assessed Elgg using privacy detail specification (PDS) derived from our 7C methodology and recommended a list of plug-ins to augment its privacy protection.
\end{abstract}

Index Terms-Alumni system, privacy guideline, privacy enhancing, elgg.

\section{INTRODUCTION}

The information base grows rapidly under alumni activities. They share personal information, post comments, tag photos and so on. This comes under malicious or unintentional disclosure through powerful tools or search engines such as Google, Bing, and various intelligence applications that drill down into personal data. Alumni usually do not remember what personal information they gave to their alma mater while a student or engaged in alumni activities. Also, public institutions do not have adequate privacy expertises or funding to design and to continue enhancing their alumni system's privacy protection. This research surveyed and studied features of alumni and social system from various sources such as software shopping guide, alumni sites policy, OECD, privacy methodologies, technologies, privacy patterns, TRUSTe privacy requirements, and so on to create an alumni privacy analysis guideline for stronger privacy protection. We introduced a document called Privacy Detail Specification (PDS) and 7C Privacy Analysis Methodology consisting of Content, Confidential, Connectivity, Consent, Constraint, Control, and Construct. The 7C Privacy Analysis Methodology will be useful for developer, designer, auditor, and user to cope with privacy protection of their system.

\section{Alumni Membership SerVice}

An alumni site is a powerful online community for communication between alumni and their alma mater. This

Manuscript received December 9, 2012; revised March 10, 2013

Kittisak Sa-adaem is with Computer Science, Computer Engineering Department, Chulalongkorn University, Bangkok, Thailand (email: cpe_me@hotmail.com).

Yunyong Teng-amnuay is with Information Systems Engineering Laboratory, Computer Engineering Department, Chulalongkorn University, Bangkok, Thailand (e-mail: Yunyong.T@chula.ac.th). includes sharing personal activities, searching schoolmate, enrolling in an event, sharing knowledge, updating news, and so on. From CAPTERRA [1], a popular software shopping guide website, and existing detail design documents [2], [3], users of alumni site can be grouped as follows.

1) Anonymous users can search and view content that depends on consent of member and regulator constraint.

2) Alumni can login, deactivate, set privacy options, manage owner profile, data and relationship, do file sharing, post status, comment, register alumni event, access forum page, view another blog/profile, find alumni member, and use reporting service.

3) Group/Data administrator can manage event, group, use data sharing, set privacy options, and reporting.

4) System administrator can manage site content, account, role, group, sent mass mail, import/export data, and reporting.

5) Third-party user can access and use agreed upon information.

\section{DATA PRIVACY}

\section{A. Privacy Principle}

Privacy allows an individual or group to reveal themselves selectively. Privacy uses the theory of natural rights, and generally responds to new information and communication technologies. In North America, Samuel D. Warren and Louis D. Brandeis wrote that privacy is the "right to be let alone" and focused on protecting individuals [4]. Kavakli et al. [5] summarized privacy requirement as

1) Anonymity: This is being virtually invisible or can be online without being tracked.

2) Pseudonymity: This is the ability to use a resource or service by acting under one or many pseudonyms, thus hiding real identity.

3) Unlinkability: This expresses the inability to link related information.

4) Unobservability: This protects users from being observed or tracked while browsing or using a service.

\section{B. Privacy Constrain}

In Thailand, the government passed laws for protecting personal information based on [6] the Organisation for Economic Co-operation and Development (OECD) [7]: guidelines. The guidelines cover personal information in the public and private sectors since 1980 [8] and represent an international consensus on how best to balance privacy protection with the free flow of personal data, are technology-neutral, flexible, allow for various means of compliance in all environments and have been put to use in 
various national regulatory and self-regulatory instruments. We also studied and included TRUSTe privacy requirement. TRUSTe is the leading online privacy solutions provider [9]. TRUSTe's privacy seal is recognized and trusted by millions of consumers.

\section{RELATED WORK}

\section{A. Privacy Protection}

The Privacy Enhancing Technologies (PETs) [10] is a generic term for a set of computer tools, applications and mechanisms which allow online services to protect the privacy of their customers' personally identifiable information (PII). PETs can be categorized as administrative tools, information tools, anonimizer tools, pseudonymizer tools, track and evident erasers and encryption tools. [11].

Kalloniatis et al. [11] introduced eight privacy process patterns namely identification, authentication, authorization, data protection, anonymity, pseudonymity, unlinkability, and unobservability.

Bouguettaya et al. [12] presented taxonomy of technologyand regulation-enabled solution for privacy preservation in the Web such as VPN, Firewall, PGP, Onion routing, etc.

Kavakli et al. [5] presented basic privacy requirement that should be considered during system design and development. They also introduced privacy implementation techniques that realize theses such as Anonimizer, Crowds, and Onion Routing.

\section{B. Social Network Software}

Deng et al. [13] presented misuse cases of social network 2.0 for privacy requirements and suggested mitigation strategies and techniques based LINDDUN privacy threat modeling methodology, and PETs.

Omar et al. [14] defined the primary and secondary social features and conducted an extensive evaluate for open source Web Content Management System (WCMSs) to facilitate Social Network Websites (SNWs). This incidentally Elgg was ranked as choice number 2 of open source WCMSs.

Curry et al. [15] presented an on-line collaborative data management system built on top of Elgg. They presented two reasons why Elgg is an ideal choice. Firstly, Elgg provides a powerful access control system that allows the owner to specify for any piece of content who can access and who can modify it. Secondly, the data in Elgg is extremely flexible, and allows arbitrary metadata to be applied to any object in the system. This is a strong baseline for building privacy-oriented alumni service.

\section{Research Methodology}

Our research methodology is depicted in Fig. 1. We analysed alumni website functionalities, then surveyed and gathered privacy requirements from multiple sources. Privacy knowledge are then gleaned from this analysis process. Analysis on privacy knowledge resulted in 7C Privacy Analysis Methodology, and Privacy Detail Specification (PDS). We created 7C Alumni Privacy Guideline based on 7C Privacy Analysis Methodology. We used the guideline to audit Elgg and suggested its existing plug-ins to support privacy protection. We leave those features unsupported by Elgg and its plug-ins for future consideration.

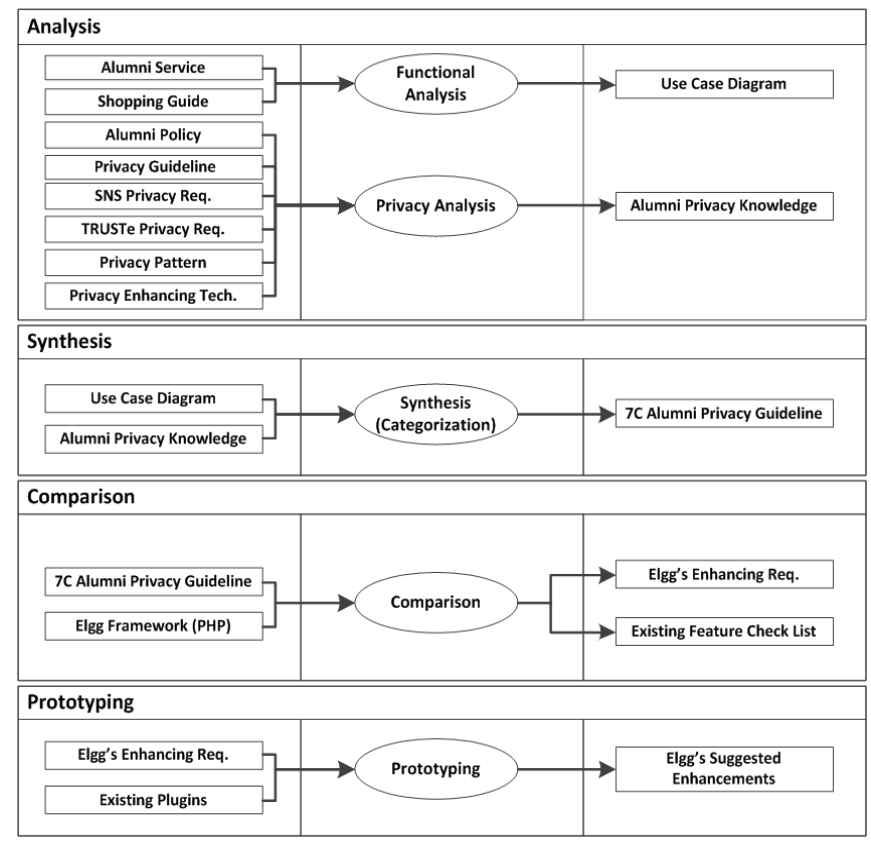

Fig. 1. Research methodology

\section{7C PRIVACy Analysis Methodology}

Analysis of privacy knowledge resulted in 7C Methodology. This makes it easier to grasp the complexity of the methodology. The "seven C's" are Content, Confidentiality, Connectivity, Consent, Constraint, Control, and Construct. Relationship of these 7 processes is depicted in Fig. 2 and each procedure is described below.

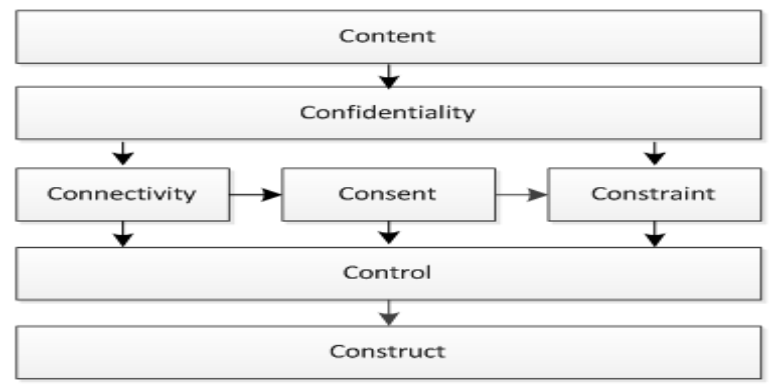

Fig. 2. Flow of 7C Privacy Analysis Methodology

\section{A. Content}

The first $\mathrm{C}$ is to gather and understand every piece of content in the system. In information architecture for the World Wide Web, Lou Rosenfeld and Peter Morville wrote, "We define content broadly as 'the stuff in your Web site.' This may include documents, data, applications, e-services, images, audio and video files, personal web pages, archived e-mail messages, and more [16]. All content are needed to be included. The list can be gathered from use-cases or software requirement specification. However, it is more convenient to extract content from screen shots and report forms as it is directly related to the use on "connectivity", described below. An example of content based on screen shot Elgg is depicted in Fig. 3. 


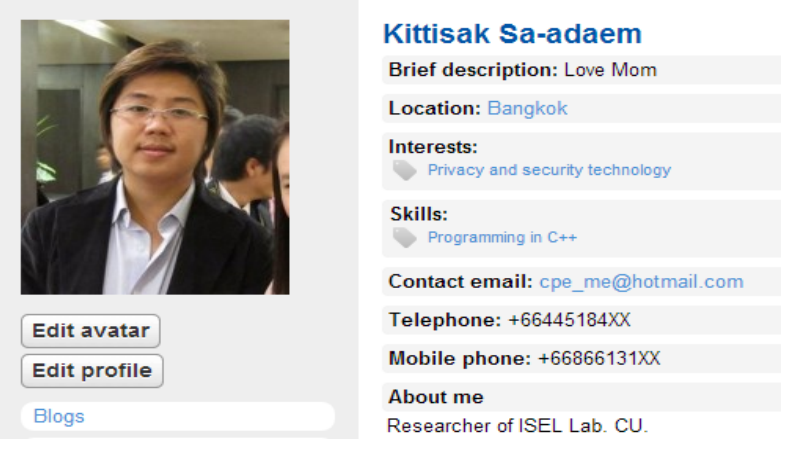

Fig. 3. Sample Elgg's personal profile.

\section{B. Confidentiality}

The second $\mathrm{C}$ is to specify which content consists of personal information that should be protected by system. To mark which attribute is personal information, US, UK, COPPA, EU, and other countries have defined list of personal data [17] and personal identifiable information (PII) [18], [19]. Following the definition of personal information, we can see that first name, last name, brief description, location, interests, skill, email, telephone, mobile phone number, and about me in Fig. 3 are personal information that should be marked as confidential. It is important to understand the difference between privacy and confidentiality [20] before starting this process:

1) Privacy is related to a person. For example a person may not want to be seen entering a place that might adversely affect their integrity, such as a pregnancy counselling centre.

2) Confidentiality refers to agreement about how a person's identifiable private information will be handled, managed, and disseminated.

\section{Connectivity}

The third $\mathrm{C}$ lists all connectivity and details each privilege between a function/service and personal information. Connectivity between a function/service and personal information that happen during use includes creating, reading, updating, and deleting. For example, as users update their locations or telephone numbers, anonymous search, or read alumni profile. Connectivity can be gathered from use cases, software requirement specification, and sequence diagrams.

\section{Consent}

The forth $\mathrm{C}$ lists all fields that the system allows alumni to control their disclosure for invoked connectivity such as mobile number, email, interests, and location. Essential fields, which are protected data, and theirs can be edited without verification can be credit card number, student ID, citizen ID, and so on. If the site does not support alumni consent functionality, alumni will react by not doing business with the site [21]. All consent required attributes depend on site policy and law.

Normal consent implies alumni consent on the private information already obtained from the customer and the service would like to give it (to third party). This implies the customer must implicitly, by default, give consent to the "primal" privacy information given to the service when accepting or applying for membership. In the concept of primal consent, customer must give consent to each piece of information required for membership registration and this will tie in with the level of service the customer will receive.

At present, all services have a very coarse grain consent, i.e., if the customer needs the service then the customer have to give consent to a lump-sum package of personnel information to obtain a package of services. A more fine-grained service and consent pairing should be developed. A customer may withhold his birthday and will not receive gift voucher on his birthday. If he deems the voucher valuable enough he will give consent for the service to obtain his birthday by providing the information himself. This kind of consent granularity can evolve into a trust relationship between the customer and the service.

\section{E. Constraint}

The fifth $\mathrm{C}$ is to survey and list all rules, regulators, and guidelines. Usually constraint depends on country and service provider. All constraints will help site to enable privacy protection and to protect itself not to violate privacy law.

\section{F. Control}

The sixth $\mathrm{C}$ is to specify privacy control for each constraint. At the start of this research, we surveyed privacy enhancing frameworks and guidelines. We found LINDDUN framework to applicable [13]. Kumari's requirement analysis for privacy in social networks [22] and Intel's privacy requirements and recommendations [23] are also useful to follow and apply. To fulfill LINDDUN's web 2.0 suggested mitigation strategies and techniques, we merged Intel's privacy requirements and recommendations into entity/user (U), data store (DS), data flow (DF), and process (P) as targets for controls. We also matched privacy process patterns [11] with LINDDUN's threat categories to support designer working on software design phase as depicted in Table I. The result of merging LINDDUN's, Kumari's, and Intel's is shown in table name "Control", a member of privacy detail specification in Fig. 5.

TABLE I: MAPPING LINDDUN THREAT CATEGORY WITH PRIVACY PROCESS PATTERN AND GUIDELINE

\begin{tabular}{|c|c|c|c|c|c|c|}
\hline $\begin{array}{l}\text { LINDDUN's } \\
\text { threat category }\end{array}$ & $\begin{array}{c}\text { Privacy } \\
\text { Properties }\end{array}$ & $\mathrm{E}$ & $\begin{array}{l}\mathrm{D} \\
\mathrm{F}\end{array}$ & $\begin{array}{l}\mathrm{D} \\
\mathrm{S}\end{array}$ & $\mathrm{P}$ & $\begin{array}{l}\text { Pattern/ } \\
\text { Guideline }\end{array}$ \\
\hline Linkability & Unlinkability & $\mathrm{x}$ & $\mathrm{x}$ & $\mathrm{x}$ & $\mathrm{x}$ & Unlinkability \\
\hline Identifiability & $\begin{array}{l}\text { Anonymity and } \\
\text { Pseudonymity }\end{array}$ & $\mathrm{x}$ & $\mathrm{x}$ & $\mathrm{x}$ & $\mathrm{x}$ & $\begin{array}{l}\text { Anonymity } \\
\text { Pseudonymity }\end{array}$ \\
\hline Non-repudiation & $\begin{array}{l}\text { Plauusible } \\
\text { deniability }\end{array}$ & & $\mathrm{x}$ & $\mathrm{x}$ & $\mathrm{x}$ & \\
\hline Detectability & $\begin{array}{l}\text { Undetectability } \\
\text { and } \\
\text { Unobservability }\end{array}$ & & $\mathrm{x}$ & $\mathrm{x}$ & $\mathrm{x}$ & Unobservability \\
\hline $\begin{array}{l}\text { Information } \\
\text { Disclosure }\end{array}$ & Confidentiality & & $x$ & $\mathrm{x}$ & $\mathrm{x}$ & $\begin{array}{l}\text { Authentication } \\
\text { Authorization } \\
\text { Identification } \\
\text { Data Protection }\end{array}$ \\
\hline $\begin{array}{l}\text { Content } \\
\text { Unawareness }\end{array}$ & $\begin{array}{l}\text { Content } \\
\text { awareness }\end{array}$ & $\mathrm{x}$ & & & & $\begin{array}{l}\text { OECD \& } \\
\text { TRUSTe }\end{array}$ \\
\hline $\begin{array}{l}\text { Policy/Consent } \\
\text { Noncompliance }\end{array}$ & $\begin{array}{l}\text { Policy and } \\
\text { Consent } \\
\text { compliance }\end{array}$ & $\mathrm{x}$ & $\mathrm{x}$ & $\mathrm{x}$ & $\mathrm{x}$ & $\begin{array}{l}\text { OECD \& } \\
\text { TRUSTe }\end{array}$ \\
\hline
\end{tabular}

\section{G. Construct}

The seventh $\mathrm{C}$ is to select PETs [10], security technology, some software finesses technique to affect privacy control, 
and anonymity related implementation such as k-anonymity [13], Tor [24], and so on. Designer can select PETs by matching with privacy process pattern in Figure 4. Moreover, Deng et al. [13] also provided table of mapping privacy objectives with PETs. Selecting suitable PETs depends on budget, system architecture, scalability, level of privacy protection, time to market, and so on. The security safeguard is very important to ensure privacy protection, and because it is the first time of defense to prevent and protect intruder from accessing personal information. Many security recommendations are suggested in [12], [24]-[26] such as firewall, SSL, HTTPS, and so on.

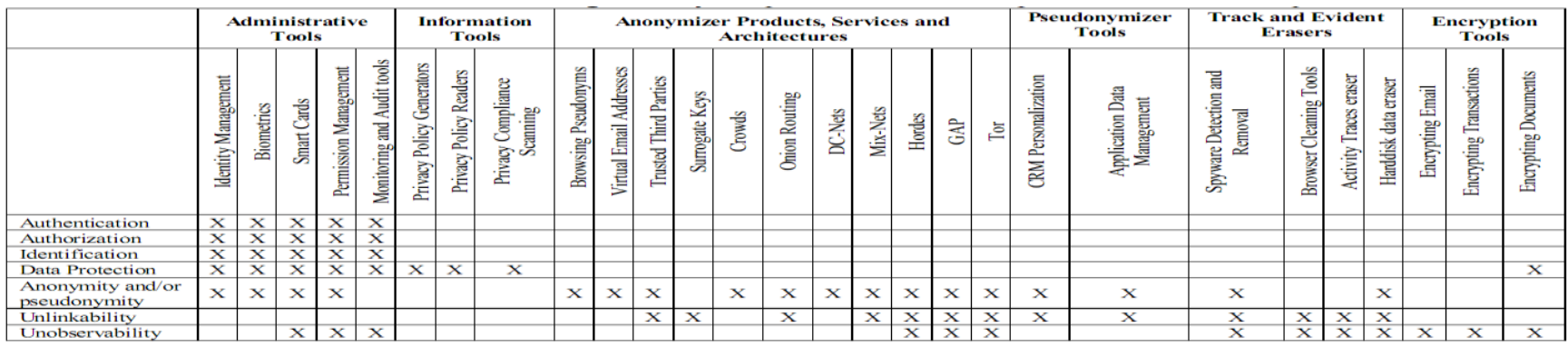

Fig. 4. Mapping between privacy process patterns and PETs.

VII. RESULT

\section{A. A Sample Privacy Detail Specification of Alumni Service}

When applying the 7C to an alumni service we obtain its Privacy Detail Specification, or PDS. A sample of the PDS is depicted in Fig. 5.

\section{B. Assessing Elgg}

We studied handbook of Elgg version 1.8 [26], reviewed Elgg's plug-ins [27], related researches [14], [15] and online recommends [28]-[30]. We found Elgg has 1653 plug-ins and 39 of these are apparently privacy enhancing related. List of Elgg's core functionalities and plug-ins to support privacy protection is presented in Table II.

We assessed Elgg version 1.8 based on our recommended 23 privacy related features as summarized from PDS in Fig. 5. There are 4 features not supported by Elgg and its existing plug-ins, and 9 privacy related plug-ins support only the previous Elgg version 1.7. The four missing features are primal consent, disabling search engine, unlinkability, and unobservability. These are feature that should be present in alumni or similar social network system. For example, Facebook service allows users to prevent search engines like Google to access their data ("who can look me up" [31]).

\section{Primal Consent on Privacy Policy}

Table III shows the page count of privacy agreement by well-known sites. These agreements are written in obscure and difficult-to-understand lawyer language. A privacy agreement usually aims at course grained consent by the customer. There are even controversies on this issue [32].

TABLE III: TOTAL NUMBER OF PAGES OF POPULAR SITE'S POLICY

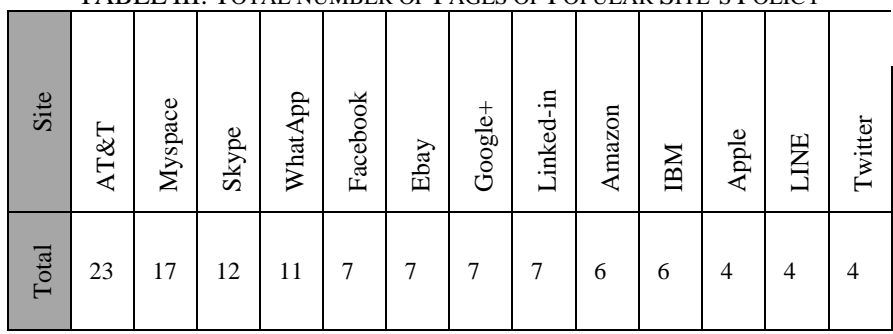

TABLE II: ASSESSING ELGG

\begin{tabular}{|c|c|c|c|}
\hline $\begin{array}{c}\text { Recommended } \\
\text { Privacy related } \\
\text { features }\end{array}$ & $\begin{array}{c}\text { Elgg } \\
1.8 \\
\text { Core } \\
\end{array}$ & Elgg 1.7 Plug-ins & Elgg 1.8 Plug-ins \\
\hline Choice on agreement & & & Registration Term 1.2.1 \\
\hline $\begin{array}{c}\text { Mandatory fields } \\
\text { control }\end{array}$ & & & Profile Manager 7.5 \\
\hline \multicolumn{4}{|l|}{ Primal consent } \\
\hline $\begin{array}{c}\text { Registration } \\
\text { validation } \\
\end{array}$ & $\mathrm{x}$ & Site Access 2.6 & $\begin{array}{c}\text { User validation by admin } \\
1.0 \\
\end{array}$ \\
\hline Privacy by default & $\mathrm{x}$ & & \\
\hline Data retention period & & & Expirationdate 1.8 .1 \\
\hline $\begin{array}{c}\text { Fine-grain access } \\
\text { control }\end{array}$ & $\mathrm{x}$ & & $\begin{array}{c}\text { SW Social Privacy } \\
\text { Concord }\end{array}$ \\
\hline $\begin{array}{l}\text { Role base access } \\
\text { control }\end{array}$ & & $\begin{array}{c}\text { Group access } \\
1.2 .2\end{array}$ & $\begin{array}{c}\text { Access Collection } \\
\text { Management 1.0.0, } \\
\text { Roles for Elgg 1.0.0, } \\
\text { Group Administrators } \\
1.0 .0 \\
\end{array}$ \\
\hline Individual access & $\mathrm{x}$ & & \\
\hline Easy privacy setting & $\mathrm{x}$ & & \\
\hline $\begin{array}{c}\text { Disclosure over } \\
\text { consent }\end{array}$ & $\mathrm{x}$ & & \\
\hline $\begin{array}{c}\text { Transferring after } \\
\text { consent }\end{array}$ & & & $\begin{array}{c}\text { Social Share Privacy } \\
1.8-12.01 .22 \\
\end{array}$ \\
\hline $\begin{array}{l}\text { Authentication and } \\
\text { identity }\end{array}$ & $\mathrm{x}$ & $\begin{array}{c}\text { Linkedin service } \\
1.0, \\
\text { Login by Email } \\
0.2, \\
\text { CAS Auth } 0.2, \\
\text { OpenID client } \\
1.3 \\
\end{array}$ & $\begin{array}{c}\text { Persona 1.0, SAML } \\
\text { authentication 1.3, } \\
\text { Simple Google } \\
\text { Authentication 1.1, } \\
\text { LDAP authentication } \\
0.2 \text {, Facebook Connect } \\
\text { Login } 1.1\end{array}$ \\
\hline \multicolumn{4}{|l|}{$\begin{array}{l}\text { Disable search } \\
\text { engine }\end{array}$} \\
\hline $\begin{array}{c}\text { Blocking and } \\
\text { backlist }\end{array}$ & $\mathrm{x}$ & & $\begin{array}{c}\text { Lee's block user 1.0.4, } \\
\text { Spam Throttle 1.5 } \\
\end{array}$ \\
\hline $\begin{array}{c}\begin{array}{c}\text { Privacy leak } \\
\text { monitoring }\end{array} \\
\end{array}$ & $\mathrm{x}$ & & $\begin{array}{c}\text { Who viewed me 1.1, } \\
\text { Advance Statistics } 0.1\end{array}$ \\
\hline $\begin{array}{l}\text { User feedback } \\
\text { channel }\end{array}$ & & $\begin{array}{l}\text { Help Chat/Live } \\
\text { Support \& Site } \\
\text { Feedback } 0.1 \\
\end{array}$ & $\begin{array}{c}\text { Questions and Answers } \\
1.0, \text { Brainstorm your } \\
\text { Elgg 0.4 } \\
\end{array}$ \\
\hline $\begin{array}{l}\text { User deactivate } \\
\text { cleaner }\end{array}$ & $\mathrm{x}$ & $\begin{array}{c}\text { Westor deleteMe } \\
1.1\end{array}$ & $\begin{array}{c}\text { Site Cron 1.8.9, } \\
\text { Comasis Cancel Account } \\
\text { 1.8, Member Selfdelete } \\
1.0 \\
\end{array}$ \\
\hline Anonymity & $\mathrm{x}$ & & Disqus Elgg 2 \\
\hline Pseudonimity & $\mathrm{x}$ & & Tabbed Profile 1.7 \\
\hline \multicolumn{4}{|l|}{ Unlinkabiblity } \\
\hline \multicolumn{4}{|l|}{ Unobservability } \\
\hline Security safeguards & $\mathrm{x}$ & $\begin{array}{c}\text { Password } \\
\text { expiration } 1.1\end{array}$ & $\begin{array}{c}\text { Spam checker 1.8.2, } \\
\text { Upgrade Key 1.0, } \\
\text { Image CAPTCHA 2.0, } \\
\text { Spam Login Filter 1.8.2, } \\
\text { Elgg-crypt 1.8.0 }\end{array}$ \\
\hline
\end{tabular}


Content:

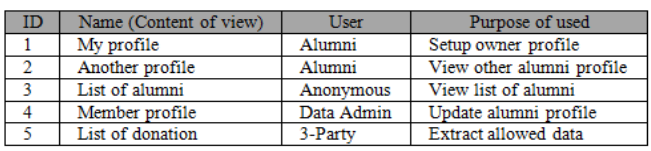

Confidentiality: $\mathrm{e}=$ Existing, and Cte\#=Content's ID

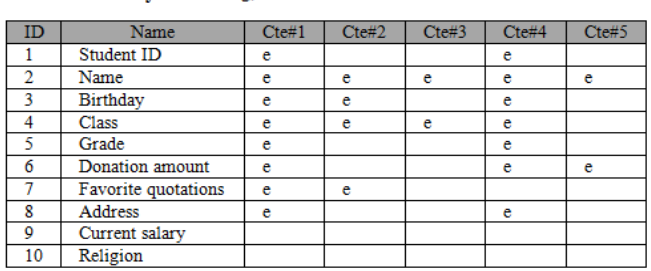

Connectivity: $a=$ Allow.

\begin{tabular}{|c|c|c|c|c|c|c|}
\hline ID & Content's Name & Confidentiality's Name & $\mathrm{C}$ & $\mathrm{R}$ & $\mathrm{U}$ & $\mathrm{D}$ \\
\hline 1 & My profile & Student ID & & $\mathrm{a}$ & & \\
\hline 2 & My profile & Name & & $\mathrm{a}$ & & \\
\hline 3 & My profile & Birthday & & $\mathrm{a}$ & & \\
\hline 4 & My profile & Class & & $\mathrm{a}$ & & \\
\hline 5 & My profile & Grade & & a & & \\
\hline 6 & My profile & Donation amount & & $\mathrm{a}$ & & \\
\hline 7 & My profile & Favorite quotations & $\mathrm{a}$ & $\mathrm{a}$ & $\mathrm{a}$ & $\mathrm{a}$ \\
\hline 8 & My profile & Address & $\mathrm{a}$ & $\mathrm{a}$ & $\mathrm{a}$ & \\
\hline 9 & Another profile & Name & & $\mathrm{a}$ & & \\
\hline 10 & Another profile & Class & & a & & \\
\hline 11 & Another profile & Birthday & & $\mathrm{a}$ & & \\
\hline 12 & Another profile & Favorite quotations & & $\mathrm{a}$ & & \\
\hline 13 & List of alumni & Name & & $\mathrm{a}$ & & \\
\hline 14 & List of alumni & Class & & $\mathrm{a}$ & & \\
\hline 15 & Member profile & Student ID & $\mathrm{a}$ & $\mathrm{a}$ & $\mathrm{a}$ & \\
\hline 16 & Member profile & Name & $\mathrm{a}$ & $\mathrm{a}$ & $\mathrm{a}$ & \\
\hline 17 & Member profile & Birthday & $\mathrm{a}$ & & & $\mathrm{a}$ \\
\hline 18 & Member profile & Class & $a$ & $\mathrm{a}$ & $\mathrm{a}$ & \\
\hline 19 & Member profile & Grade & $\mathrm{a}$ & & $\mathrm{a}$ & \\
\hline 21 & Member profile & Donation amount & $\mathrm{a}$ & & $\mathrm{a}$ & \\
\hline 22 & Member profile & Address & & $\mathrm{a}$ & $\mathrm{a}$ & \\
\hline 23 & List of donation & Name & & $\mathrm{a}$ & & \\
\hline 24 & List of donation & Donation amount & & $\mathrm{a}$ & & \\
\hline
\end{tabular}

Consent: $t=$ Toggle.

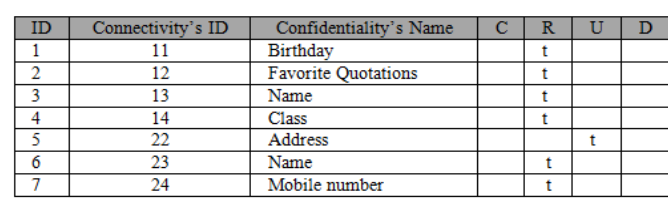

Constraint:

\begin{tabular}{|c|c|c|c|}
\hline ID & Name & Source & Constraint Detail \\
\hline 1 & $\begin{array}{l}\text { Collection } \\
\text { Limit }\end{array}$ & OECD [7] & $\begin{array}{l}\text { There should be limits to the collection of } \\
\text { personal data and any such data should be } \\
\text { obtained by lawful ... }\end{array}$ \\
\hline 2 & Data Quality & OECD & $\begin{array}{l}\text { Personal data should be accurate, complete } \\
\text { and kept up-to-date... }\end{array}$ \\
\hline 3 & $\begin{array}{l}\text { Purpose } \\
\text { Specification }\end{array}$ & $\mathrm{OECD}$ & $\begin{array}{l}\text { The purposes for which personal data are } \\
\text { collected should be specified.... }\end{array}$ \\
\hline 4 & Use Limitation & OECD & $\begin{array}{l}\text { Personal data should not be disclosed, made } \\
\text { available or otherwise used for purposes... }\end{array}$ \\
\hline 5 & $\begin{array}{l}\text { Security } \\
\text { Safeguards }\end{array}$ & OECD & $\begin{array}{l}\text { Personal data should be protected by } \\
\text { reasonable security safeguards against... }\end{array}$ \\
\hline 6 & Openness & OECD & $\begin{array}{l}\text { There should be a general policy of openness } \\
\text { about developments ... with respect to } \\
\text { personal data ... }\end{array}$ \\
\hline 7 & $\begin{array}{l}\text { Individual } \\
\text { Participation }\end{array}$ & OECD & $\begin{array}{l}\text { An individual should have the right a) to } \\
\text { obtain from a data controller, or otherwise... }\end{array}$ \\
\hline 8 & Accountability & OECD & $\begin{array}{l}\text { A data controller should be accountable for } \\
\text { complying with measures ... }\end{array}$ \\
\hline 9 & $\begin{array}{l}\text { Consent and } \\
\text { Choice }\end{array}$ & $\begin{array}{l}\text { Bevanda et al. } \\
\text { [33] }\end{array}$ & $\begin{array}{l}\text { The purpose associated with personal } \\
\text { information shall have consent of the donor } \\
\text { of personal information }\end{array}$ \\
\hline 10 & Data Retention & TRUSTe [9] & $\begin{array}{l}\text { The time period of retention PII, How log } \\
\text { system will retain that information. }\end{array}$ \\
\hline 11 & $\begin{array}{l}\text { Third Party and } \\
\text { Transborder }\end{array}$ & $\begin{array}{l}\text { Skinner et al. } \\
\text { [34] }\end{array}$ & $\begin{array}{l}\text { The information system may not transfer } \\
\text { information to a third party or foreign } \\
\text { country without the consent of the individual }\end{array}$ \\
\hline 12 & Search Service & TRUSTe & $\begin{array}{l}\text { The system shall provide the individual a } \\
\text { mechanism to stop having their information } \\
\text { displayed in search result. }\end{array}$ \\
\hline 13 & Anonymity & Skinner et al. & $\begin{array}{l}\text { The information system should be done in } \\
\text { way that supports anonymity for the } \\
\text { individual user. }\end{array}$ \\
\hline 14 & Pseudonymity & $\begin{array}{l}\text { Kavakli et al. } \\
\text { [5] }\end{array}$ & $\begin{array}{l}\text { System should provide ability to use a } \\
\text { resource or service by acting under one or } \\
\text { many pseudonyms, thus hiding real identity. }\end{array}$ \\
\hline 15 & Unlinkability & Kavakli et al. & $\begin{array}{l}\text { System should provide inability to link } \\
\text { related personal information. }\end{array}$ \\
\hline 16 & Unobservability & Kavakli et al. & $\begin{array}{l}\text { System should protect users from being } \\
\text { observed while browsing or using a service. }\end{array}$ \\
\hline
\end{tabular}

Control:

\begin{tabular}{|c|c|c|}
\hline ID & Type & How to control software design and development. \\
\hline 1 & Collection Limit & $\begin{array}{l}\text { Data Store) Do not retain information longer than necessary. Do not } \\
\text { collect individual's personal information if not needed. } \\
\text { User) Use feedback tools to raise user's privacy awareness. }\end{array}$ \\
\hline 2 & Data Quality & $\begin{array}{l}\text { Process) All personal information about an individual must be available to } \\
\text { that individual and allow them to make corrections and update. }\end{array}$ \\
\hline 3 & $\begin{array}{l}\text { Purpose } \\
\text { Specification }\end{array}$ & $\begin{array}{l}\text { User) } \\
\text { 1. The user must be informed about what is being collected, and why and } \\
\text { whether the information will be shared with anyone else. } \\
\text { 2. Provide brief description of your privacy policy with a link to more } \\
\text { detailed version. }\end{array}$ \\
\hline 4 & Use Limitation & $\begin{array}{l}\text { Process) } \\
\text { 1. Personal information may only be used for the purpose described in the } \\
\text { notice. } \\
\text { 2. Apply access control according to user's privacy preference }\end{array}$ \\
\hline 5 & Security Safeguards & $\begin{array}{l}\text { Data Store) Protected by reasonable security safeguards. } \\
\text { Data Flow) When collecting personal information online, implement } \\
\text { encryption techniques, and employ secure communication. } \\
\text { Process) } \\
\text { 1. Use principle of least privilege. } \\
\text { 2. Avoid display object references whenever possible. } \\
\text { 3. Confirm that user has the necessary privileges and authorization. } \\
\text { 4. Avoid the use of custom cookies. } \\
\text { 5. Validate input to a guard against Cross-Site Scripting. } \\
6 \text {. Completing a code review. }\end{array}$ \\
\hline 6 & Openness & $\begin{array}{l}\text { User) The information system must have documented and make easily } \\
\text { available its policies on personal information. }\end{array}$ \\
\hline 7 & $\begin{array}{l}\text { Individual } \\
\text { Participation }\end{array}$ & $\begin{array}{l}\text { Process) } \\
\text { 1. Allow the individual to maintain his own personal information. } \\
\text { 2. Use a secure user profile. }\end{array}$ \\
\hline 8 & Accountability & $\begin{array}{l}\text { 1. Appoint employee responsible for policy compliance or hire external } \\
\text { company for compliancy auditing. } \\
2 . \text { Ensure training obligation for employees. }\end{array}$ \\
\hline 9 & Consent and Choice & $\begin{array}{l}\text { Process) } \\
\text { 1. Obtain affirmative opt-in consent from an individual before collecting } \\
\text { their personal information. } \\
\text { 2. Inform the individual of their choices and require the individual to select } \\
\text { before proceeding. } \\
\text { User) Add a convenient location in the source for personal information } \\
\text { handling practices. }\end{array}$ \\
\hline 10 & Data Retention & $\begin{array}{l}\text { Data Store) All personal information should have expiration date. } \\
\text { User) Inform how long you will retain the personal information. }\end{array}$ \\
\hline 11 & $\begin{array}{l}\text { Third party and } \\
\text { Transborder }\end{array}$ & $\begin{array}{l}\text { Process) Obtain the user's permission before sharing collected personal } \\
\text { information with third parties. } \\
\text { User) When transferring the personal information to third parties, you need } \\
\text { to inform the individual. You need to honor their decision }\end{array}$ \\
\hline 12 & Search Service & $\begin{array}{l}\text { Process) Provide mechanism to stop having their information displayed in } \\
\text { search result. } \\
\text { User) Privacy statement shall state how individual can remove their } \\
\text { information from displayed search result. }\end{array}$ \\
\hline 13 & Anonymity & $\begin{array}{l}\text { Data Store) Apply data anonymization techniques, and enforce data } \\
\text { protection by means of relationship-based access control. } \\
\text { Data Flow) Deploy anonymity system for communication between user } \\
\text { and site. } \\
\text { Process) Use identity management to ensure unlinkability. }\end{array}$ \\
\hline 14 & Pseudonymize & $\begin{array}{l}\text { Process) Apply secure pseudonumization techniques to issue pseudonyms } \\
\text { as user IDs. } \\
\text { User) Use privacy awareness: Inform users using real ID runs a risk for } \\
\text { privacy violation. }\end{array}$ \\
\hline 15 & Unlinkability & $\begin{array}{l}\text { Data Store) Apply data anonymization techniques. } \\
\text { Data Flow) Deploy anonymity system. } \\
\text { Process) Deploy anonymity system to support unlinkability of } \\
\text { pseudonyms. } \\
\text { User) Use privacy awareness: Inform users that revealing too much } \\
\text { information online can be privacy invasive. }\end{array}$ \\
\hline 16 & Unobservability & $\begin{array}{l}\text { Data Store) Use sufficient access control and information hiding } \\
\text { techniques. } \\
\text { Data Flow) Covert channel and steganography can be used to protect } \\
\text { privacy. }\end{array}$ \\
\hline
\end{tabular}

Construct:

\begin{tabular}{|c|c|c|c|}
\hline ID & Name & Short Detail & Control Type \\
\hline 1 & $\mathrm{~K}$-anonymity & $\begin{array}{l}\text { Each individual's record is indistinguishable } \\
\text { from at least } k-1 \text { other's records. }\end{array}$ & Anonymization technique \\
\hline 2 & Pseudonymization & Render the data record less identifying. & $\begin{array}{l}\text { Pseudonymization } \\
\text { technique }\end{array}$ \\
\hline 3 & Feedback & To raise user's privacy awareness. & Privacy Awareness \\
\hline 4 & Primal consent & $\begin{array}{l}\text { To explicitly allow individual of their } \\
\text { choices in providing privacy information } \\
\text { using options, radio buttons, etc. }\end{array}$ & Consent \& Choice \\
\hline 5 & Site's Policy & A statement or a legal document. & Privacy Awareness \\
\hline 6 & OpenID & $\begin{array}{l}\text { Allows users to be authenticated by certain } \\
\text { co-operating sites. }\end{array}$ & Authentication \& Identity \\
\hline 7 & XACML & $\begin{array}{l}\text { Access control policy language implemented } \\
\text { in XML }\end{array}$ & Access Control \\
\hline 8 & LDAP & Lightweight Directory Access Protocol. & Access Control \\
\hline 9 & Tor & $\begin{array}{l}\text { The Onion Router is a system intended for } \\
\text { online anonymity. }\end{array}$ & Anonymity System \\
\hline 12 & HTTPS & Hypertext Transfer Protocol Secure. & Security Safeguards \\
\hline 13 & SNORT & Network intrusion prevention system. & Security Safeguards \\
\hline 14 & Firewall & $\begin{array}{l}\text { Prevent unauthorized communications } \\
\text { between computer networks or hosts. }\end{array}$ & Security Safeguards \\
\hline 15 & P3P & $\begin{array}{l}\text { A protocol allowing websites to declare their } \\
\text { intended use of information they collect } \\
\text { about web browser users. }\end{array}$ & Security Safeguards \\
\hline
\end{tabular}

Fig. 5. A sample Privacy Detail Specification of Alumni Service

\section{CONCLUSION AND FUTURE WORK}

Privacy protection is related to many constituent parts such as consents, laws, control methodologies, security technologies, and so on. This is not easy for a person who is not a privacy expert. To make privacy enhancing process 
easier, we introduced 7C. This will be helpful for stakeholders to deal with various aspects of privacy protections in their system. Applying the methodology to alumni service will result in Privacy Detail Specification which aids in privacy protection of the service.

Elgg is a popular open-source social network software and has good roadmap. It is suitable for use as our prototype alumni system for assessment on privacy. To fulfill privacy protection, developer and designer select suitable existing plug-ins and build new plug-ins for missing controls. Thus our work extends from simply assessment to a more practical guideline as compared to previous work [35].

Our research also indicates that the primal consent is important and should not be ignored. Currently systems collect their member personal information in term of package with very coarse granularity. The granularity of consent over personal information is neglected during use by system, transfer to third party, or when member exchange their personal information with site to receive some services. Our future work is the development of Elgg's plug-ins to support privacy protection based on concept of primal consent and privacy requirements that Elgg does not support via current core functionality and existing plug-ins.

\section{REFERENCES}

[1] CAPTERRA. Alumni Management Software Programs. [Online]. Available: http://www.capterra.com/alumni-management-software

[2] L. Jarupakwittaya and H. Naknarong, "Alumni Management System," Senior Project, Dept. CS, Khon Kaen Univ., Thailand, 2009.

[3] T. Jaiswal and R. Zhu, "Software Requirements Specification for Larkut.com," Herguan Univ., Sunnyvale, CA, 2010.

[4] Wikipedia. Privacy. [Online]. http://en.wikipedia.org/wiki/Privacy.

[5] E. Kavakli, C. Kalloniatis, and S. Gritzalis , "Addressing privacy: matching user requirements to implementation techniques," in Proc. the 7th Hellenic European Research on Computer Mathematics \& its Applications Conf., Athens, Greece, September 22 - 24, 2005.

[6] RTGS. Notification on the Electronic Transactions Commission on Policy and practice Statement on Personal Data Protection of a Government Agency 2010. [Online]. Available: http://www.ratchakitcha.soc.go.th/DATA/PDF/2553/E/126/31.PDF

[7] OECD. About the OECD. [Online]. Available: http://www.oecd.org/about/.

[8] OECD. Privacy and Personal Data Protection. [Online]. Available: http://www.oecd.org/sti/interneteconomy/37626097.pdf.

[9] TRUSTe. Privacy Program Requirements. [Online]. Available: http://www.truste.com/privacy-program-requirements.

[10] Wikipedia. Privacy-enhancing technologies. [Online]. Available: http://en.wikipedia.org/wiki/Privacy-enhancing_technologies.

[11] C. Kalloniatis, E. Kavakli, and S. Gritzalis, "Using Privacy Process Patterns for Incorporating Privacy Requirements into the System Design Process," in Proc. the 2sd International Conf. on Availability, Reliability and Security, pp. 1009-1017, April 10-13 2007

[12] A. R. A. Bouguettaya and M. Y. Eltoweissy, "Privacy on the Web: facts, challenges, and solutions," IEEE Security \& Privacy, vol. 1, no. 6, pp. 40- 49, Nov.-Dec. 2003.

[13] M. Deng, K. Wuyts, R. Scandariato, B. Preneel, and W. Joosen, "A privacy threat analysis framework: supporting the elicitation and fulfillment of privacy requirements," Requirements Engineering, vol. 16, no. 1, pp 3-32, 2011.

[14] O. Al-hamdi and A. Salah, "Open Source Web Content Management Systems to Build Social Network Websites," International Journal of Reviews in Computing, vol. 11, pp. 48-60, Sep. 30, 2012.

[15] R. Curry, C. Kiddle, R. Simmonds, and G. Z. Pastorello, "An on-line collaborative data management system," Gateway Computing Environments Workshop, pp. 1-10, Nov. 14, 2010

[16] Wikipedia. Web content. [Online]. http://en.wikipedia.org/wiki/Web_content

[17] The IT Law Wiki. Personal Data. [Online]. Available: http://itlaw.wikia.com/wiki/Personal_data.

[18] The IT Law Wiki. Personally identifiable information. [Online]. Available: http://itlaw.wikia.com/wiki/Personally_identifiable_information
[19] Wikipedia. Personally identifiable information. [Online]. Available: http://en.wikipedia.org/wiki/Personal_information

[20] UT Health Science Center. Do you know the difference between Privacy and Confidential? [Online]. Available: http://research.uthscsa.edu/ocr/Privacy\%20and\%20Confidentiality\%2 0in\%20Human\%20Research.pdf

[21] L. L. Lobato, E. B. Fernandez, and S. D. Zorzo, "Patterns to Support the Development of Privacy Policies," in Proc. International Conf. on Availability, Reliability and Security, pp. 744-749, March 16-19, 2009.

[22] P. Kumari, "Requirements analysis for privacy in social networks," in Proc. 8th International Workshop for Technical, Economic and Legal Aspects of Business Models for Virtual Goods, Namur, October 2010.

[23] Privacy Requirements and Recommendations for Application Development for the Intel AppUp developer program: What Application Developers Should Know. [Online]. Available: http://software.intel.com/en-us/articles/privacy-requirements-and-reco mmendations-for-application-development-for-the-intel-appupsm.

[24] S. Romanosky, A. Acquisti, J. Hong, L. F. Cranor, and B. Friedman, "Privacy patterns for online interactions," in Proc. of the conf. on Pattern languages of programs, ACM, NY, USA, Article 12, 2006.

[25] A. G. Abbasi, S. Muftic, and I. Hotamov, "Web Contents Protection, Secure Execution and Authorized Distribution," 5th International Multi-Conf. on Computing in the Global Information Technology, pp. 157-162, Sep. 20-25, 2010

[26] C. Costello, Elgg 1.8 Social Networking, 2sd ed., Birmingham, B3, 2PB, UK, Feb, 2012.

[27] Elgg. Welcome to Elgg's plugin directory. [Online]. Available: http://community.elgg.org/plugins

[28] Wikipedia. Comparison of social networking software. [Online] Available:

http://en.wikipedia.org/wiki/Comparison_of_social_networking_soft ware

[29] D. Fory. Social Network / Community / Forum Software Comparison Chart. [Online]. Available: http://www.deanflory.com/articles/social_software_comparison

[30] M. Sharma. Users, Profiles, and Connections in Elgg. (April, 2008). [Online].

Available http://www.packtpub.com/article/users-profiles-and-connections-in-el $\mathrm{gg}$

[31] Facebook. Making Your Settings Easier to Find: Dig Into the Details. [Online]. Available: https://www.facebook.com/about/details.

[32] AppleInsider. US congressmen inquire about iOS privacy with Apple, 33 developers. [Online]. Available: http://appleinsider.com/articles/12/03/22/us_congress men_inquire_about_ios_privacy_with_apple_33_developers

[33] V. Bevanda, J. Azemovic, and D. Music, "Privacy Preserving in eLearning Environment (Case of Modeling Hippocratic Database Structure)," presented at 4th Balkan Conf. in Informatics, pp. 47-52 Sep.17-19, 2009.

[34] G. Skinner, S. Han, and E. Chang, "A framework of privacy shield in organizational information systems," International Conf. on Mobile Business, pp. 647- 650, July 11-13, 2005.

[35] D. W. Yu, S. Doddapaneni, and S. Murthy, "A Privacy Assessment Approach for Serviced Oriented Architecture Application," 2sd IEEE International Workshop in Service-Oriented System Engineering, pp. 67-75, Oct. 2006

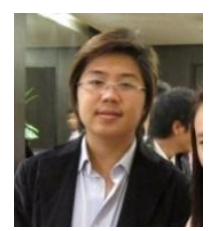

Kittisak Sa-Adaem was born in Surin, Thailand in 1982. He graduated from Kasetsart University with Bachelor Degree in Computer Engineering. $\mathrm{He}$ is currently a master student in Computer Science, a member of Information Systems Engineering Laboratory in the Department of Computer Engineering, Chulalongkorn University, and a senior SM in Telecom Billing System of Amdocs (Thailand) Co., Ltd

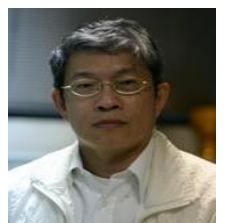

Yunyong Teng-Amnuay was born in Bangkok, Thailand in 1954. He graduated from Chulalongkorn University with Bachelor Degree in Electrical Engineering and Master Degree in Computer Science. $\mathrm{He}$ obtained Ph.D. in Computer Science from Iowa State University, U.S.A, in 1984. His expertises are in system software, distributed systems, networking, and information system architecture. He is currently a lecturer and the director of Information Systems Engineering Laboratory of the Department of Computer Engineering, Chulalongkorn University. 